\title{
Determinants of acquired disability and recovery from disability in Indian older adults: longitudinal influence of socio- economic and health-related factors
}

\author{
Ronak Paul[D, Shobhit Srivastava(B), T. Muhammad(D) and Rashmi Rashmi id
}

\begin{abstract}
Background: There is a higher burden of functional disability for Indian older adults with substantial variations across different geographic regions and socioeconomic groups as compared to other ageing Asian countries. Thus, using a national sample of older adults aged 60+ years, we aim to explore how common is acquiring of disability and recovery from disability among the older population of a developing country like India, and how do the various socioeconomic and health-related conditions impact this transition in disability status.
\end{abstract}

Method: The current study uses two waves of the India Human Development Survey (IHDS) and is based on panel data of 10,527 older adults. Both bivariate and multiple variable regression analysis were performed using two binary outcome variables in this study - whether older adults acquired disability and recovered from disability between round-I and round-II, respectively.

Results: Nearly $31.5 \%$ and $4.4 \%$ of older adults have acquired and recovered disability across the two rounds respectively. About $38.5 \%$ and $45.8 \%$ of female older adults' disability status changes to disable and recovered in round-II respectively. A lesser proportion of older adults have recovered from a disability who have a chronic disease in round-I. Cataract chronic conditions among older adults in round-I had shown 1.45 times (Cl: 1.07-1.97) a significantly higher likelihood of acquiring disability in round-I. Older adults who were unmarried and were not working in round-I have 1.12 times (Cl: 1.01-1.25) and 1.21 times (Cl: 1.06-1.39) higher likelihood of acquiring disability in round-II respectively. Recovering from disability was mostly seen among older adults who belong to the richest (OR: 2.38, Cl: 1.31-4.33) and medium (OR: 2.16, Cl: 1.27-3.69) wealth quintile households. Older adults residing in the central region of India have 2.72 times (Cl: 2.31-3.19) significantly higher chance of acquiring disability than those who were residing in northern regions.

Conclusion: Appropriate measures are required to highlight the importance of chronic physical diseases and several socio-demographic factors that may negatively affect the trajectory of disability in older ages.

Keywords: Activities of daily living, Change in disability status, Recovery from disability, Incidence of disability, Elderly, India Human Development Survey

\footnotetext{
*Correspondence: rashmir635@gmail.com

International Institute for Population Sciences, Maharashtra 400088 Mumbai, India
}

(c) The Author(s). 2021 Open Access This article is licensed under a Creative Commons Attribution 4.0 International License, which permits use, sharing, adaptation, distribution and reproduction in any medium or format, as long as you give appropriate credit to the original author(s) and the source, provide a link to the Creative Commons licence, and indicate if changes were made. The images or other third party material in this article are included in the article's Creative Commons licence, unless indicated otherwise in a credit line to the material. If material is not included in the article's Creative Commons licence and your intended use is not permitted by statutory regulation or exceeds the permitted use, you will need to obtain permission directly from the copyright holder. To view a copy of this licence, visit http://creativecommons.org/licenses/by/4.0/ The Creative Commons Public Domain Dedication waiver (http://creativecommons.org/publicdomain/zero/1.0/) applies to the data made available in this article, unless otherwise stated in a credit line to the data. 


\section{Background}

Due to the on-going demographic transition towards an ageing population, there is an increasing trend in the prevalence of late-life disabilities especially in developing countries $[1,2]$. Disability in old age is common and becomes a stress factor for individual's family as well as the society at large due to the limited resources for assistance, care and rehabilitation [3, 4]. While experiencing a double burden of both communicable and noncommunicable diseases [5], three-fourth of the Indian population aged 50 and above are suffering from some form of disability [6]. At the same time, a positive relationship between disability and poverty in low and middle income countries has been documented in the recent literature [7].

Multiple studies found that older age, female sex, being widowed or single, sedentary physical activity, obesity, smoking, or having chronic diseases are commonly associated with disability [8-10]. The literature on gender differences in functional limitations and disabilities has shown a female disadvantage [11-13]. Besides, older people with low socioeconomic status, lower levels of education, less engaged in social activities, not in the working force, and have poor health status were more likely to have disabilities [14-17]. Studies based on World Health Organization (WHO) Study on Global Ageing and adult health (SAGE) data have explored the association between sociodemographic factors, chronic diseases, and disability $[13,18-20]$, and found education and employmentdriven inequalities in the prevalence of disability and its concentration in the rural areas of the developing countries. However, a review of resilience literature talking about the ability of older individuals to maintain a positive mental state during exposure to health problems shows that those living in rural areas might show signs of high resilience by overcoming socioeconomic obstacles and being able to live a decent life despite declining health and the presence of multiple functional limitations [21].

Furthermore, factors associated with no recovery from disability were chronic diseases, depression, older age, female gender, and low educational level [22]. Similarly, in a community-based study, a greater number of limitations in functional health was shown as a predictor of failing to recover from disabilities in old age [23]. On the other hand, a recent study among older Mexican adults suggested that older individuals with several chronic conditions such as heart disease at baseline were also associated with an improvement or a recovery from disabilities [24]. Findings also suggest that older adults with illnesses are often forced to alter their lifestyle and prefer better nutrition, increase physical activity and social participation and reduce or quit alcohol consumption and tobacco use thus improving their wellbeing and resulting in recovery from disabilities $[25,26]$.

It is however demonstrated that older women have a lower probability than older men of recovering after reporting functional limitations [27]. The study also revealed that living alone and other socio-demographic factors that include caste and family structure played a significant role in disability dynamics [28, 29]. Further, several studies in India have demonstrated a higher likelihood of being sick and disabled among older adults who are economically disadvantaged and belonged to lower caste groups [30, 31]. It is again observed that currently married status and living with spouse and children were negatively associated with the prevalence of disability or remaining disabled [32-35].

Besides, a higher burden of functional disability for Indian older adults with substantial variations across different geographic regions and socioeconomic groups has been reported in multiple studies as compared to other ageing Asian countries [29, 36-38]. Although a couple of studies observed the greater socioeconomic inequalities in disability among older Indian adults $[11,39]$ and their treatment seeking behaviour [40], a better knowledge of the determinants of changes in the disability status will be helpful from the perspective of targeting the most vulnerable groups and establishing preventive health priorities among the older population. Since existing studies on physical limitations highlight the determinants of late-life disabilities, we focus on the associated factors of recovery from or acquiring of disability in old age. Thus, using a national sample of older Indian adults aged $60+$, the present study aims to explore how common is acquiring of disability and recovery from disability among the older population of a developing country like India, and how do the various socioeconomic and health-related conditions impact this transition in disability status.

\section{Data, Variables and Methods \\ Data source}

This study used round-I and round-II of the India $\mathrm{Hu}$ man Development Survey (IHDS). IHDS round-I, conducted during 2005, is a nationally representative and multi-topic survey of 41,554 households across all the states and union territories of India except for Andaman \& Nicobar Islands and Lakshadweep [41]. IHDS roundII, conducted in 2012, is also a nationally representative and multi-topic survey of 42,152 households with geographical coverage similar to round-I [42]. IHDS roundII re-interviewed $83 \%$ of the households from round-I. Both rounds of IHDS adopted a multistage stratified random sampling design. Further details regarding the IHDS sampling frame, data collection procedure and respondent consent can be found elsewhere [43, 44]. 
This study is based on older adults aged $60+$ years who participated in both rounds of IHDS. During IHDS round-I (baseline survey), there were 17,904 individuals and among them, 4736 older adults were not alive and 2641 older adults were lost to follow-up during roundII. Therefore, our current study is based on panel data of 10,527 older adults. Additionally, there were no records with missing information for all the variables used in our study.

\section{Outcome variables}

We used two binary outcome variables in this study whether older adults acquired disability and recovered from disability between round-I and round-II, respectively. Both these outcome indicators were obtained from an older adult's self-reported disability status during both rounds of IHDS. During both rounds, IHDS asked respondents that whether they had difficulty in - "walking $1 \mathrm{~km}$ ", "going to the toilet without help", "dressing without help", "hearing normal conversation", "speaking normally", "seeing distant things" and "seeing near objects such as reading/sewing". Responses to these seven questions were coded as "0" (No difficulty), "1" (With difficulty) and "2" (Unable to do it). We summed the coded responses for each person to obtain a disability score ranging from 0 to 14 and found the median disability score to be 0 in both rounds. Therefore, older adults with a score of 0 were classified as "not disabled" and with a score above 0 were classified as "disabled".

In the acquired disability variable (no, yes), among the older adults who were not disabled in 2005, those were disabled during 2012 were categorized as "yes" and those who were not disabled during both 2005 and 2012 were categorized into "no" respectively. Equivalently, in the recovered from disability variable (no, yes), older adults who were disabled in 2005 but were not disabled during 2012 were categorized as "yes" and those who were disabled in both rounds were categorized into "no".

\section{Independent variables}

Existing studies have shown several factors, which influences the change in disability status among older adults. We controlled for the effects of the majority of these explanatory variables, conditional to their availability in the IHDS dataset. The demographic and social control variables related to the older adults include - gender of individual (male, female), age group (60-69 years, 70-79 years, $80+$ years), current marital status (currently married, currently not married), level of education (no formal schooling, less than 5 years of schooling, 6-10 years of schooling, more than 10 years of schooling), current work status (currently working, currently not working). Additionally, we included self-reported indicators of chronic illness indicating whether an older adult has - cardiovascular diseases (no, yes), hypertension (no, yes), diabetes (no, yes), respiratory illness (no, yes), cataract (no, yes) and any other chronic illness other than the above (no, yes). We also controlled for relevant household socio-economic characteristics - headship status (no, yes), family structure (joint/extended, nuclear, single generation), wealth quintile (poorest, poor, medium, rich, richest), household below poverty line (BPL) status (no, yes), the caste of household (scheduled tribes (ST), scheduled castes (SC), other backward classes (OBC), others), the religion of household (Hindu, Muslim, others), place of residence (urban, rural). Additionally, we also included the country region that a person comes from (northern, north-eastern, central, eastern, western, southern). All the above characteristics were measured for the older adults during round-I.

During round-I IHDS collected information on the marital status of each person and originally categorized them into six categories - "spouse absent", "married", "single", "widowed", and "separated/divorced". Owing to the skewed population distribution across each category, we have recoded the original variable into a binary marital status variable (currently married, currently not married). Here, all individuals not included in the "married" category in the original variable were included in the "currently not married" category of the recoded variable.

During round-I, IHDS obtained the information on whether each person reportedly suffered from - cataract, tuberculosis, hypertension, cardiovascular diseases, diabetes, leprosy, cancer, asthma, polio, paralysis, epilepsy, mental illness, sexually transmitted diseases (STD) and any other chronic disease. If an older adult suffered from the above chronic diseases, then they were coded as "yes" and otherwise they were coded as "no".

Household family structure was obtained from the information given on the relationship of each household member with the head of the household. Based on this information we classified the family structure into - single generation, nuclear and joint/extended family. The single generation includes a married/cohabiting couple or a single person household. The nuclear family includes married/cohabiting partners along with their dependent and unmarried children. The joint family includes a parent and/or partner along with their children and grandchildren. The extended family is similar to a joint family structure with the exception that it also includes "extended members", that is, people who are not directly related to the household head by blood.

The household wealth quintile for round-I was calculated using principal component analysis [45]. We generated a wealth score for each household using the available information on household asset ownership, livestock ownership, building material used in household, household water source, household sanitation 
facility and the number of rooms. Based on the wealth score we categorized the households into five categories (poorest, poor, medium, rich, and richest).

IHDS classified caste of the household head into five categories (Brahmin, Other Backward Caste (OBC), Schedule Caste (SC), Schedule Tribe (ST), Others). We recoded the caste variable into four categories - "OBC", "SC", "ST" and "Other", where the "Other" category consists of "Brahmin" and "Other" categories from the original variable. The people in the ST and SC category belong to the most socially backward group of people who historically belonged to the lower rung of the now constitutionally-abolished Indian caste system. People in the OBC category, as the name suggests, also belong to a group of the socially and economically backward population, with conditions better than that of the SC/ST population. The "Other" category consists of all people who do not belong to either of the three caste groups.

The country regions during round-I were formed by grouping the erstwhile 33 states and union territories of India into six regions. The northern region includes Chandigarh, Delhi, Haryana, Himachal Pradesh, erstwhile Jammu \& Kashmir, Punjab, Uttaranchal and Rajasthan. The north-eastern region includes Assam, Arunachal Pradesh, Manipur, Meghalaya, Mizoram, Nagaland, Tripura and Sikkim. The central region consists of Madhya Pradesh and Chhattisgarh. The eastern region includes Bihar, Jharkhand, Odisha and West Bengal. The western region comprises Dadra \& Nagar Haveli, Daman \& Diu, Goa, Gujarat and Maharashtra. The southern region comprises erstwhile Andhra Pradesh, Karnataka, Kerala, Tamil Nadu and Pondicherry.

\section{Statistical methods}

We performed bivariate and multivariate analysis to achieve the study objectives. Bivariate and multivariate analysis was performed in two sets by taking "acquired disability" and "recovered from disability" as the outcome variable respectively. The first set involved those older adults who were not disabled in round-I, and among them, we examined the factors responsible for acquiring disability in round-II. The second set examined the factors associated with recovery from disability in round-II among those older adults who were disabled in round-I. Owing to the binary nature of the outcome variable, bivariate analysis was done using the chi-square test for association. Equivalently, multivariate analysis was performed by estimating multivariable logistic regression models. Odds ratios in the multivariable models show the association between the outcome variables of change in disability status and the predictor variables. The odds ratio for the first set, measures the odds of acquiring disability relative to having no disability among the older adults belonging to a particular category of an explanatory variable given the effect of all the other explanatory variables remain constant [46]. Similarly, the odds ratio for the second set, gives the odds of recovery from disability relative to the older adults who had disability given the effect of the other independent variables are constant. The odds ratio can take any value above zero, with a value between 0 and 1 denoting a negative association, and a value more than 1 denoting a positive association.

Additionally, we checked for multicollinearity in both the regression models and found the mean value of the variance inflation factor (VIF) to be less than 1.35. Thus, our estimated regression models do not suffer from multicollinearity. All the statistical estimations were performed using the STATA software version 14.2 [47].

\section{Results}

\section{Descriptive Statistics}

Figure 1 provides a cross-sectional view of disability status among older adults in India. In the IHDS panel, we see that $9 \%$ of older adults had a disability in 2005 , however, the percentage increased to $37 \%$ in 2012. Figure 2 presents the change in disability status of older adults across the two rounds of IHDS. Results show that 32\% and $4 \%$ of older adults had acquired disability and recovered from disability across rounds-I and -II respectively.

Table 1 shows the characteristics of 10,527 older adults in the IHDS panel dataset during 2005. Among the panel of older adults, we found that $52 \%$ were females and $33 \%$ were not married during round-I. Further, six in every ten older adults had no formal schooling and $15 \%$ were working during 2005 . Moreover, half of the older adults were household heads and three-fourth lived in a joint/extended family. Nearly $32 \%$ and $20 \%$ of older adults lived in the lowest $40 \%$ wealth quintile and below poverty line households respectively. Furthermore, one in every five older adults belonged to the SC/ST caste and $74 \%$ lived in rural communities. Additionally, $33 \%$ of older adults resided in the northern Indian states followed by $24 \%$ of older adults in the southern region.

We compared the percentage distribution of the population of older adults across selected characteristics for both the full sample and panel sample in round-I (baseline), as shown in the last column of Table 1. Indeed, the percentage distribution across the individual-related, household-related and socioeconomic characteristics were similar among both datasets. Only the percentage distribution by age group differed by more than $5 \%$ between the two datasets.

\section{Bivariate Analysis}

The first part of Table 2 shows the association of different bio-demographic and socio-economic characteristics 


\section{Percentage of older adults by their disability status}

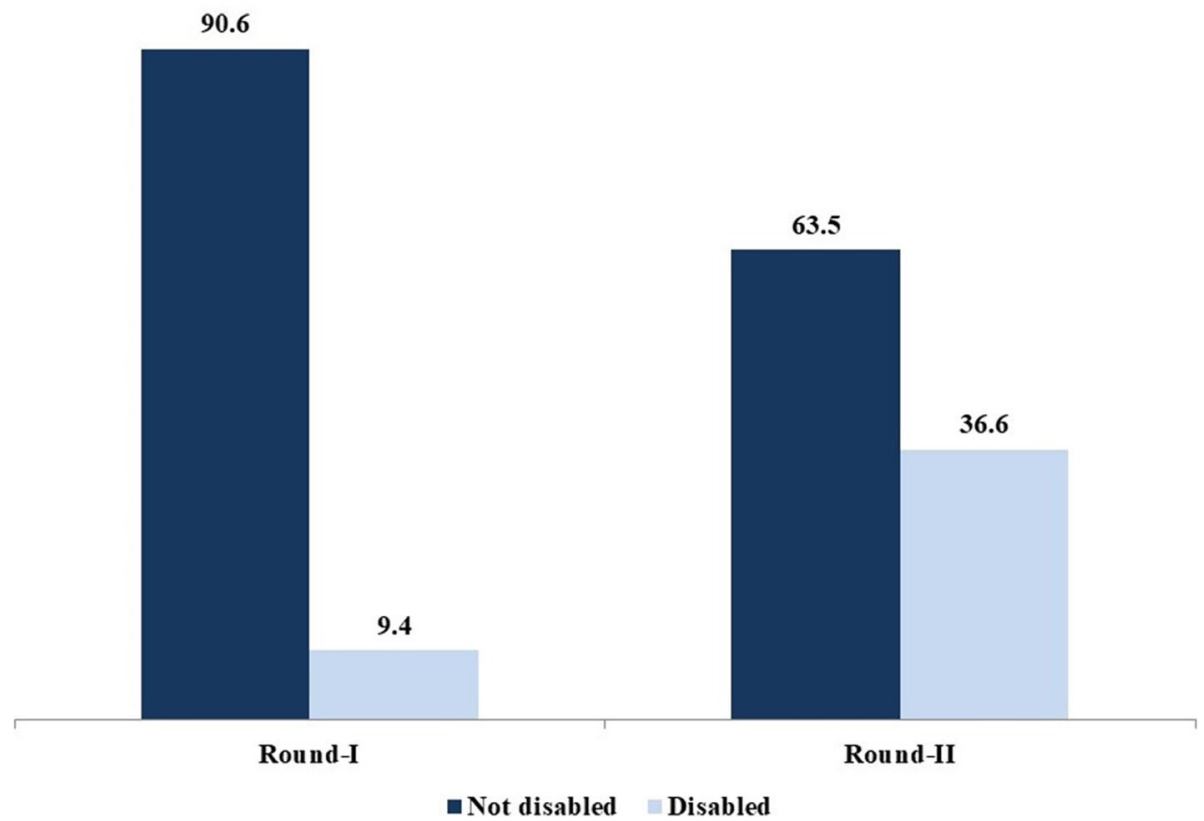

Fig. 1 Percentage distribution of older adults $(60$ + years) by the change in disability status from round-I to round-II

\section{Percentage of older adults by change in their disability status}

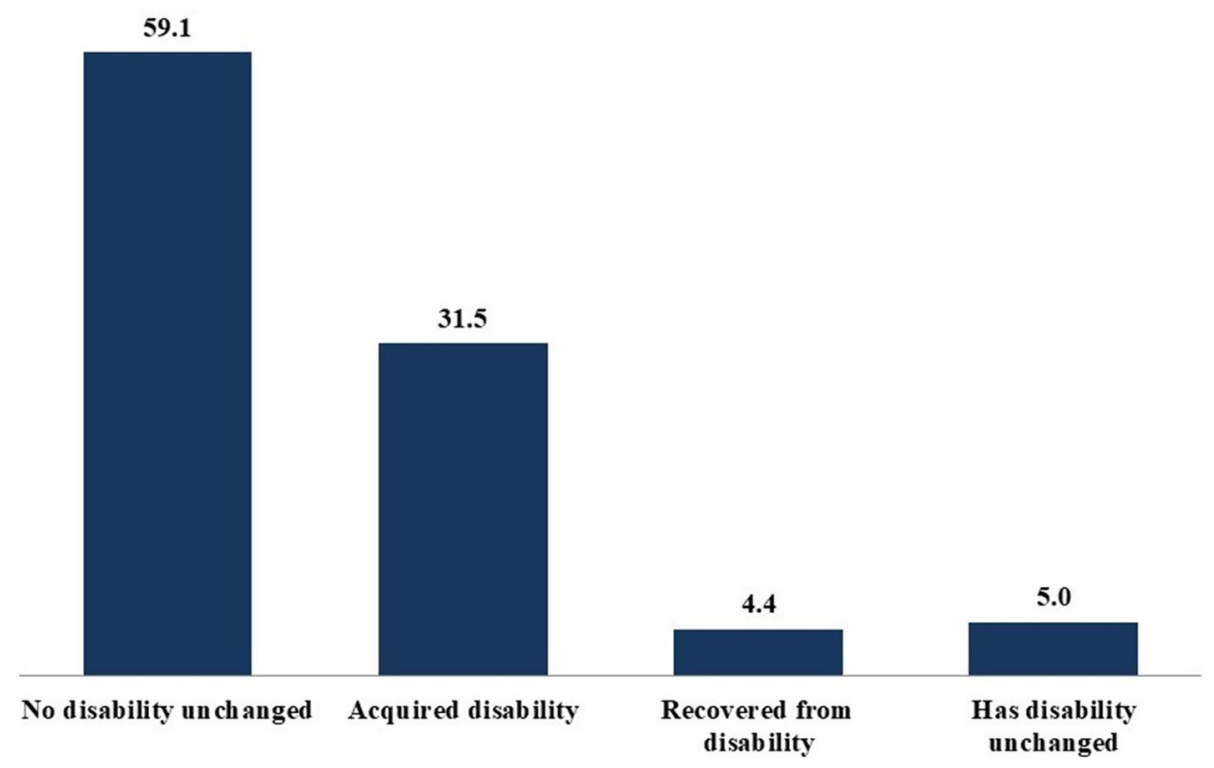

Fig. 2 Percentage distribution of older adults (60 + years) by the disability status during round-I and round-II 
Table 1 Absolute (N) and percentage (\%) distribution of older adults (60 + years) by relevant socio-economic and demographic characteristics across the full and panel sample during round-I (baseline period) in India

\begin{tabular}{|c|c|c|c|c|c|}
\hline \multirow[t]{3}{*}{ Characteristics } & \multicolumn{4}{|c|}{ IHDS round-I (Baseline Period) } & \multirow{3}{*}{$\begin{array}{l}\begin{array}{l}\text { Absolute } \\
\text { difference }\end{array} \\
\%\end{array}$} \\
\hline & \multicolumn{2}{|c|}{ Full Sample } & \multicolumn{2}{|c|}{ Panel Sample } & \\
\hline & $\bar{N}$ & $\%$ & $\mathrm{~N}$ & $\%$ & \\
\hline \multicolumn{6}{|l|}{ Gender of individual } \\
\hline Male & 8,963 & 50.1 & 5,076 & 48.2 & 1.9 \\
\hline Female & 8,941 & 49.9 & 5,451 & 51.8 & 1.9 \\
\hline \multicolumn{6}{|l|}{ Age-group (in years) } \\
\hline $60-69$ & 10,917 & 61.0 & 7,343 & 69.8 & 8.8 \\
\hline 70-79 & 5,200 & 29.0 & 2,663 & 25.3 & 3.7 \\
\hline $80+$ & 1,787 & 10.0 & 521 & 4.9 & 5.1 \\
\hline \multicolumn{6}{|l|}{ Current marital status } \\
\hline Currently married & 11,254 & 62.9 & 7,086 & 67.3 & 4.4 \\
\hline Currently not married & 6,650 & 37.1 & 3,441 & 32.7 & 4.4 \\
\hline \multicolumn{6}{|l|}{ Level of education } \\
\hline No formal schooling & 10,672 & 59.6 & 6,262 & 59.5 & 0.1 \\
\hline Less than 5 years of schooling & 3,128 & 17.5 & 1,867 & 17.7 & 0.2 \\
\hline 6-10 years of schooling & 2,736 & 15.3 & 1,622 & 15.4 & 0.1 \\
\hline More than 10 years of schooling & 1,368 & 7.6 & 776 & 7.4 & 0.2 \\
\hline \multicolumn{6}{|l|}{ Current work status } \\
\hline Currently working & 2,407 & 13.4 & 1,593 & 15.1 & 1.7 \\
\hline Currently not working & 15,497 & 86.6 & 8,934 & 84.9 & 1.7 \\
\hline \multicolumn{6}{|l|}{ Household headship status } \\
\hline No & 9,294 & 51.9 & 5,334 & 50.7 & 1.2 \\
\hline Yes & 8,610 & 48.1 & 5,193 & 49.3 & 1.2 \\
\hline \multicolumn{6}{|l|}{ Family structure } \\
\hline Joint/Extended & 13,843 & 77.3 & 8,109 & 77.0 & 0.3 \\
\hline Nuclear & 2,016 & 11.3 & 1,268 & 12.0 & 0.7 \\
\hline Single generation & 2,045 & 11.4 & 1,150 & 10.9 & 0.5 \\
\hline \multicolumn{6}{|l|}{ Household wealth quintile } \\
\hline Poorest & 2,699 & 15.1 & 1,603 & 15.2 & 0.1 \\
\hline Poor & 2,961 & 16.5 & 1,777 & 16.9 & 0.4 \\
\hline Medium & 3,491 & 19.5 & 2,109 & 20.0 & 0.5 \\
\hline Rich & 3,852 & 21.5 & 2,241 & 21.3 & 0.2 \\
\hline Richest & 4,901 & 27.4 & 2,797 & 26.6 & 0.8 \\
\hline \multicolumn{6}{|c|}{ Household below poverty line (BPL) } \\
\hline No & 14,312 & 79.9 & 8,445 & 80.2 & 0.3 \\
\hline Yes & 3,592 & 20.1 & 2,082 & 19.8 & 0.3 \\
\hline \multicolumn{6}{|l|}{ Caste of household } \\
\hline Scheduled Tribes & 1,126 & 6.3 & 607 & 5.8 & 0.5 \\
\hline Scheduled Castes & 3,167 & 17.7 & 1,858 & 17.6 & 0.1 \\
\hline Other Backward Classes & 7,191 & 40.2 & 4,334 & 41.2 & 1.0 \\
\hline Others & 6,420 & 35.9 & 3,728 & 35.4 & 0.5 \\
\hline \multicolumn{6}{|l|}{ Religion of household } \\
\hline Hindu & 14,641 & 81.8 & 8,676 & 82.4 & 0.6 \\
\hline
\end{tabular}


Table 1 Absolute (N) and percentage (\%) distribution of older adults (60 + years) by relevant socio-economic and demographic characteristics across the full and panel sample during round-I (baseline period) in India (Continued)

\begin{tabular}{|c|c|c|c|c|c|}
\hline \multirow[t]{3}{*}{ Characteristics } & \multicolumn{4}{|c|}{ IHDS round-I (Baseline Period) } & \multirow{3}{*}{$\begin{array}{l}\begin{array}{l}\text { Absolute } \\
\text { difference }\end{array} \\
\%\end{array}$} \\
\hline & \multicolumn{2}{|c|}{ Full Sample } & \multicolumn{2}{|c|}{ Panel Sample } & \\
\hline & $\mathrm{N}$ & $\%$ & $\mathrm{~N}$ & $\%$ & \\
\hline Muslim & 1,758 & 9.8 & 994 & 9.4 & 0.4 \\
\hline Others & 1,505 & 8.4 & 857 & 8.1 & 0.3 \\
\hline \multicolumn{6}{|c|}{ Participates in social groups } \\
\hline Yes & 6,362 & 35.5 & 3,813 & 36.2 & 0.7 \\
\hline No & 11,542 & 64.5 & 6,714 & 63.8 & 0.7 \\
\hline \multicolumn{6}{|c|}{ Place of residence } \\
\hline Urban & 5,257 & 29.4 & 2,764 & 26.3 & 3.1 \\
\hline Rural & 12,647 & 70.6 & 7,763 & 73.7 & 3.1 \\
\hline \multicolumn{6}{|l|}{ Country regions } \\
\hline Northern & 5,771 & 32.2 & 3,488 & 33.1 & 0.9 \\
\hline North Eastern & 562 & 3.1 & 290 & 2.8 & 0.3 \\
\hline Central & 1,728 & 9.7 & 1,029 & 9.8 & 0.1 \\
\hline Eastern & 2,637 & 14.7 & 1,599 & 15.2 & 0.5 \\
\hline Western & 2,577 & 14.4 & 1,584 & 15.0 & 0.6 \\
\hline Southern & 4,629 & 25.9 & 2,537 & 24.1 & 1.8 \\
\hline Overall & 17,904 & 100 & 10,527 & 100 & 0 \\
\hline
\end{tabular}

Note - (a) Full sample refers to the original population surveyed during the baseline period (round-l); (b) Panel sample refers to the population who were alive in both rounds of IHDS

of older adults in round-I with their acquired disability status during round-II. Among 9533 older adults who were not disabled in round-I, $35 \%$ acquired disability in round-II. We observed that female older adults (38\%) and elderly in the age group of $80+$ years (52\%) were highly likely to acquire disability during round-II. Further, older adults who had hypertension, cataract, or any other chronic condition had greater likelihood of acquired the disability. Moreover, $40 \%$ of unmarried older adults and $37 \%$ older adults who were not head of the household became disabled between rounds-I and -II. Furthermore, acquiring disability was more common among older adults residing in a single generation family (42\%), poorest wealth quintile (39\%) and below poverty line households (37\%). The proportion of older adults becoming disabled in round-II was highest in the Central region (58\%) followed by the Southern (41\%) and Northern (34\%) regions respectively.

Similarly, the second part of Table 2 shows the association of explanatory characteristics in round-I with the recovery of disability among older adults during roundII. Among 994 older adults who were disabled in roundI, $47 \%$ recovered from their disability between round-I and round-II. Recovery from disability was higher among older adults (52\%) in the 60-69 age group. Although the proportion of recovery from disability was higher among older adults who had no chronic diseases during
round-I, the bivariate association was not statistically significant at the $5 \%$ level. Moreover, $42 \%$ of older adults who did not participate in social groups and $53 \%$ elderly living in urban communities recovered from disability between rounds-I and -II. Additionally, the proportion of older adults recovering from disability was highest in the North-eastern region (67\%) followed by the Eastern (66\%) and Western (58\%) regions respectively.

\section{Multivariate Analysis}

Table 3 show the results from logistic regression models indicating the association of explanatory characteristics of in round-I with the transition of disability status in older adults between rounds-I and -II. We see that, female older adults had 1.40 times (CI: 1.21-1.61) significantly higher odds of acquiring disability in round-II. Moreover, with the growing age the likelihood of acquiring disability among older adults increases; and their chance of recovering from disability decreases significantly. Further, we observed that older adults with cataract chronic conditions in round-I had 1.45 times (CI: 1.07-1.97) higher odds of acquiring disability by roundII. Older adults who were not married and were residing in single generation family in round-I have 1.12 times (CI: $1.01-1.25$ ) and 1.35 times (CI: $1.16-1.57$ ) greater likelihood of acquiring disability by round-II respectively. 
Table 2 Bivariate analysis showing the association of bio-demographic and socio-economic characteristics in round-I with the acquiring and recovery from disability in round-II respectively among panel data of older adults (60 + years) in India

\begin{tabular}{|c|c|c|c|c|c|c|c|c|}
\hline \multirow[t]{3}{*}{ Characteristics } & \multicolumn{8}{|c|}{ Change in disability status during round-II } \\
\hline & \multirow{2}{*}{$\begin{array}{l}\text { Total } \\
\mathrm{N}\end{array}$} & \multicolumn{3}{|c|}{ Disability acquired } & \multirow{2}{*}{$\begin{array}{l}\text { Total } \\
\mathrm{N}\end{array}$} & \multicolumn{3}{|c|}{ Disability recovered } \\
\hline & & $\bar{N}$ & $\%$ & $x 2$ tests & & $\mathrm{N}$ & $\%$ & $x 2$ tests \\
\hline \multicolumn{9}{|l|}{ Gender of individual } \\
\hline Male & 4,654 & 1,440 & 30.9 & \multirow{2}{*}{$\begin{array}{l}\boldsymbol{x} 2=59.56 \\
p \text {-value }=0.001\end{array}$} & 422 & 201 & 47.6 & \multirow{2}{*}{$\begin{array}{l}\boldsymbol{x} 2=0.32 \\
p \text {-value }=0.568\end{array}$} \\
\hline Female & 4,879 & 1,877 & 38.5 & & 572 & 262 & 45.8 & \\
\hline \multicolumn{9}{|l|}{ Age-group (in years) } \\
\hline $60-69$ & 6,755 & 2,102 & 31.1 & \multirow{3}{*}{$\begin{array}{l}\boldsymbol{x} 2=152.14 \\
p \text {-value }=0.001\end{array}$} & 588 & 303 & 51.5 & \multirow{3}{*}{$\begin{array}{l}\boldsymbol{x} 2=14.85 \\
p \text {-value }=0.001\end{array}$} \\
\hline 70-79 & 2,331 & 985 & 42.3 & & 332 & 134 & 40.4 & \\
\hline $80+$ & 447 & 230 & 51.5 & & 74 & 26 & 35.1 & \\
\hline \multicolumn{9}{|l|}{ Had Cardiovascular diseases } \\
\hline No & 9,400 & 3,263 & 34.7 & \multirow{2}{*}{$\begin{array}{l}\boldsymbol{x} 2=2.00 \\
p \text {-value }=0.157\end{array}$} & 952 & 448 & 47.1 & \multirow{2}{*}{$\begin{array}{l}\boldsymbol{x} 2=2.08 \\
p \text {-value }=0.149\end{array}$} \\
\hline Yes & 133 & 54 & 40.6 & & 42 & 15 & 35.7 & \\
\hline \multicolumn{9}{|l|}{ Had Hypertension } \\
\hline No & 9,030 & 3,115 & 34.5 & \multirow{2}{*}{$\begin{array}{l}\boldsymbol{x} 2=6.73 \\
p \text {-value }=0.009\end{array}$} & 825 & 389 & 47.2 & \multirow{2}{*}{$\begin{array}{l}\boldsymbol{x} 2=0.64 \\
p \text {-value }=0.424\end{array}$} \\
\hline Yes & 503 & 202 & 40.2 & & 169 & 74 & 43.8 & \\
\hline \multicolumn{9}{|l|}{ Had Diabetes } \\
\hline No & 9,276 & 3,217 & 34.7 & \multirow{2}{*}{$\begin{array}{l}\boldsymbol{x} 2=1.97 \\
p \text {-value }=0.160\end{array}$} & 896 & 424 & 47.3 & \multirow{2}{*}{$\begin{array}{l}\boldsymbol{x} 2=2.01 \\
p \text {-value }=0.156\end{array}$} \\
\hline Yes & 257 & 100 & 38.9 & & 98 & 39 & 39.8 & \\
\hline \multicolumn{9}{|l|}{ Had Respiratory illnesses } \\
\hline No & 9,290 & 3,227 & 34.7 & \multirow{2}{*}{$\begin{array}{l}\boldsymbol{x} 2=0.55 \\
p \text {-value }=0.457\end{array}$} & 935 & 438 & 46.8 & $x_{2}=0.45$ \\
\hline Yes & 243 & 90 & 37.0 & & 59 & 25 & 42.4 & $p$-value $=0.504$ \\
\hline Had Cataract & & & & & & & & \\
\hline No & 9,346 & 3,231 & 34.6 & $\boldsymbol{x} 2=10.53$ & 867 & 408 & 47.1 & $x 2=0.63$ \\
\hline Yes & 187 & 86 & 46.0 & $p$-value $=0.001$ & 127 & 55 & 43.3 & $p$-value $=0.429$ \\
\hline Had Any other chronic illnesses & & & & & & & & \\
\hline No & 9,160 & 3,159 & 34.5 & $\boldsymbol{x} 2=9.79$ & 859 & 412 & 48.0 & $x 2=4.86$ \\
\hline Yes & 373 & 158 & 42.4 & $p$-value $=0.002$ & 135 & 51 & 37.8 & $p$-value $=0.027$ \\
\hline Current marital status & & & & & & & & \\
\hline Currently married & 6,478 & 2,097 & 32.4 & $x 2=52.34$ & 608 & 287 & 47.2 & $x 2=0.24$ \\
\hline Currently not married & 3,055 & 1,220 & 39.9 & $p$-value $=0.001$ & 386 & 176 & 45.6 & $p$-value $=0.620$ \\
\hline Level of education & & & & & & & & \\
\hline No formal schooling & 5,724 & 2,091 & 36.5 & $x 2=32.35$ & 538 & 263 & 48.9 & $x_{2}=4.04$ \\
\hline Less than 5 years of schooling & 1,646 & 575 & 34.9 & $p$-value $=0.001$ & 221 & 93 & 42.1 & $p$-value $=0.257$ \\
\hline $6-10$ years of schooling & 1,452 & 417 & 28.7 & & 170 & 74 & 43.5 & \\
\hline More than 10 years of schooling & 711 & 234 & 32.9 & & 65 & 33 & 50.8 & \\
\hline Working status & & & & & & & & \\
\hline Working & 1,505 & 466 & 31.0 & $\boldsymbol{x} 2=11.56$ & 88 & 38 & 43.2 & $x 2=0.45$ \\
\hline Not working & 8,028 & 2,851 & 35.5 & $p$-value $=0.001$ & 906 & 425 & 46.9 & $p$-value $=0.503$ \\
\hline Household headship status & & & & & & & & \\
\hline No & 4,803 & 1,792 & 37.3 & $\boldsymbol{x} 2=26.99$ & 531 & 242 & 45.6 & $x 2=0.46$ \\
\hline Yes & 4,730 & 1,525 & 32.2 & $p$-value $=0.001$ & 463 & 221 & 47.7 & $p$-value $=0.496$ \\
\hline Family structure & & & & & & & & \\
\hline Joint/Extended & 7,369 & 2,576 & 35.0 & $\begin{array}{l}\boldsymbol{x} 2=43.23 \\
p \text {-value }=0.001\end{array}$ & 740 & 342 & 46.2 & $\begin{array}{l}\boldsymbol{x} 2=1.71 \\
p \text {-value }=0.425\end{array}$ \\
\hline
\end{tabular}


Table 2 Bivariate analysis showing the association of bio-demographic and socio-economic characteristics in round-I with the acquiring and recovery from disability in round-II respectively among panel data of older adults (60 + years) in India (Continued)

\begin{tabular}{|c|c|c|c|c|c|c|c|c|}
\hline \multirow[t]{3}{*}{ Characteristics } & \multicolumn{8}{|c|}{ Change in disability status during round-II } \\
\hline & \multirow{2}{*}{$\begin{array}{l}\text { Total } \\
\mathrm{N}\end{array}$} & \multicolumn{3}{|c|}{ Disability acquired } & \multirow{2}{*}{$\begin{array}{l}\text { Total } \\
\mathrm{N}\end{array}$} & \multicolumn{3}{|c|}{ Disability recovered } \\
\hline & & $\mathrm{N}$ & $\%$ & $x 2$ tests & & $\mathbf{N}$ & $\%$ & $x 2$ tests \\
\hline Nuclear & 1,169 & 328 & 28.1 & & 99 & 52 & 52.5 & \\
\hline Single generation & 995 & 413 & 41.5 & & 155 & 69 & 44.5 & \\
\hline \multicolumn{9}{|c|}{ Household wealth quintile } \\
\hline Poorest & 1,468 & 570 & 38.8 & \multirow{5}{*}{$\begin{array}{l}\boldsymbol{x} 2=17.31 \\
p \text {-value }=0.002\end{array}$} & 135 & 54 & 40.0 & \multirow{5}{*}{$\begin{array}{l}\boldsymbol{x} 2=4.74 \\
p \text {-value }=0.315\end{array}$} \\
\hline Poor & 1,633 & 591 & 36.2 & & 144 & 66 & 45.8 & \\
\hline Medium & 1,913 & 633 & 33.1 & & 196 & 102 & 52.0 & \\
\hline Rich & 2,023 & 670 & 33.1 & & 218 & 101 & 46.3 & \\
\hline Richest & 2,496 & 853 & 34.2 & & 301 & 140 & 46.5 & \\
\hline \multicolumn{9}{|c|}{ Household below poverty line (BPL) } \\
\hline No & 7,619 & 2,605 & 34.2 & \multirow{2}{*}{$\begin{array}{l}\boldsymbol{x} 2=6.10 \\
p \text {-value }=0.013\end{array}$} & 826 & 385 & 46.6 & \multirow{2}{*}{$\begin{array}{l}\boldsymbol{x} 2=0.01 \\
p \text {-value }=0.966\end{array}$} \\
\hline Yes & 1,914 & 712 & 37.2 & & 168 & 78 & 46.4 & \\
\hline \multicolumn{9}{|l|}{ Caste of household } \\
\hline Scheduled Tribes & 563 & 177 & 31.4 & \multirow{4}{*}{$\begin{array}{l}\boldsymbol{x} 2=16.89 \\
p \text {-value }=0.001\end{array}$} & 44 & 26 & 59.1 & \multirow{4}{*}{$\begin{array}{l}\boldsymbol{x} 2=5.92 \\
p \text {-value }=0.116\end{array}$} \\
\hline Scheduled Castes & 1,723 & 613 & 35.6 & & 135 & 71 & 52.6 & \\
\hline Other Backward Classes & 3,936 & 1,447 & 36.8 & & 398 & 175 & 44.0 & \\
\hline Others & 3,311 & 1,080 & 32.6 & & 417 & 191 & 45.8 & \\
\hline \multicolumn{9}{|l|}{ Religion of household } \\
\hline Hindu & 7,897 & 2,787 & 35.3 & \multirow{3}{*}{$\begin{array}{l}\boldsymbol{x} 2=5.39 \\
p \text {-value }=0.068\end{array}$} & 779 & 367 & 47.1 & \multirow{3}{*}{$\begin{array}{l}\boldsymbol{x} 2=5.42 \\
p \text {-value }=0.067\end{array}$} \\
\hline Muslim & 898 & 285 & 31.7 & & 96 & 51 & 53.1 & \\
\hline Others & 738 & 245 & 33.2 & & 119 & 45 & 37.8 & \\
\hline \multicolumn{9}{|c|}{ Participates in social groups } \\
\hline Yes & 3,415 & 1,138 & 33.3 & \multirow{2}{*}{$\begin{array}{l}x 2=5.08 \\
p \text {-value }=0.024\end{array}$} & 398 & 165 & 41.5 & \multirow{2}{*}{$\begin{array}{l}x 2=6.99 \\
p \text {-value }=0.008\end{array}$} \\
\hline No & 6,118 & 2,179 & 35.6 & & 596 & 298 & 50.0 & \\
\hline \multicolumn{9}{|l|}{ Place of residence } \\
\hline Urban & 2,512 & 838 & 33.4 & \multirow{2}{*}{$\begin{array}{l}\boldsymbol{x} 2=3.09 \\
p \text {-value }=0.078\end{array}$} & 252 & 133 & 52.8 & \multirow{2}{*}{$\begin{array}{l}\boldsymbol{x} 2=5.21 \\
p \text {-value }=0.022\end{array}$} \\
\hline Rural & 7,021 & 2,479 & 35.3 & & 742 & 330 & 44.5 & \\
\hline \multicolumn{9}{|l|}{ Country regions } \\
\hline Northern & 3,245 & 1,090 & 33.6 & \multirow{7}{*}{$\begin{array}{l}x 2=433.49 \\
p \text {-value }=0.001\end{array}$} & 243 & 121 & 49.8 & $\boldsymbol{x} 2=48.32$ \\
\hline North Eastern & 284 & 22 & 7.7 & & 6 & 4 & 66.7 & \\
\hline Central & 937 & 539 & 57.5 & & 92 & 28 & 30.4 & \\
\hline Eastern & 1,495 & 409 & 27.4 & & 104 & 69 & 66.3 & \\
\hline Western & 1,412 & 365 & 25.8 & & 172 & 99 & 57.6 & \\
\hline Southern & 2,160 & 892 & 41.3 & & 377 & 142 & 37.7 & \\
\hline Overall & 9,533 & 3,317 & 34.8 & & 994 & 463 & 46.6 & \\
\hline
\end{tabular}

Note - (a) $\boldsymbol{x}^{2}$-tests denotes the Chi-square test for association

Notably, recovering from disability was mostly seen among older adults who belonged to the richest (OR: 2.38, CI: 1.31-4.33), rich (OR: 2.03, CI: 1.16-3.53) and medium (OR: $2.16, \mathrm{CI}: 1.27-3.69$ ) wealth quintile households in comparison to their counterparts in the poorest wealth quintile. Older adults residing in the Central region of India have 2.72 times (CI: 2.31-
3.19) significantly higher chance of acquiring disability than those who were residing in Northern regions. Additionally, recovery from disability was higher among older adults in the Eastern (OR: 2.70, CI: 1.59-4.56) and Western (OR: 1.83, CI: 1.18-2.82) regions of India respectively compared to the residents of the Northern region. 
Table 3 Odds ratio from logistic regression models showing the association of bio-demographic and socio-economic characteristics measure in round-I with acquiring and recovery from disability during round-II among panel data of older adults

\begin{tabular}{|c|c|c|c|c|}
\hline \multirow[t]{3}{*}{ Characteristics } & \multicolumn{4}{|c|}{ Change in disability status during round-II } \\
\hline & \multicolumn{2}{|c|}{ Disability acquired } & \multicolumn{2}{|c|}{ Disability recovered } \\
\hline & $\overline{O R}$ & $95 \% \mathrm{Cl}$ & OR & $95 \% \mathrm{Cl}$ \\
\hline \multicolumn{5}{|l|}{ Gender of individual } \\
\hline Male & 1.00 & & 1.00 & \\
\hline Female & $1.40^{* * *}$ & $(1.21-1.61)$ & 0.85 & $(0.56-1.29)$ \\
\hline \multicolumn{5}{|l|}{ Age-group (in years) } \\
\hline $60-69$ & 1.00 & & 1.00 & \\
\hline $70-79$ & $1.60^{* * *}$ & $(1.45-1.78)$ & $0.57^{* * *}$ & $(0.42-0.77)$ \\
\hline $80+$ & $2.27^{* * *}$ & $(1.85-2.78)$ & $0.41^{* * *}$ & $(0.23-0.72)$ \\
\hline \multicolumn{5}{|l|}{ Had Cardiovascular diseases } \\
\hline No & 1.00 & & 1.00 & \\
\hline Yes & 1.32 & $(0.91-1.91)$ & 0.59 & $(0.30-1.19)$ \\
\hline \multicolumn{5}{|l|}{ Had Hypertension } \\
\hline No & 1.00 & & 1.00 & \\
\hline Yes & 1.16 & $(0.95-1.42)$ & 1.10 & $(0.74-1.62)$ \\
\hline \multicolumn{5}{|l|}{ Had Diabetes } \\
\hline No & 1.00 & & 1.00 & \\
\hline Yes & 1.14 & $(0.86-1.50)$ & 0.74 & $(0.45-1.21)$ \\
\hline \multicolumn{5}{|l|}{ Had Respiratory illnesses } \\
\hline No & 1.00 & & 1.00 & \\
\hline Yes & 1.04 & $(0.79-1.37)$ & 0.93 & $(0.53-1.66)$ \\
\hline \multicolumn{5}{|l|}{ Had Cataract } \\
\hline No & 1.00 & & 1.00 & \\
\hline Yes & $1.45^{* *}$ & $(1.07-1.97)$ & 1.15 & $(0.76-1.76)$ \\
\hline \multicolumn{5}{|l|}{ Had Any other chronic illnesses } \\
\hline No & 1.00 & & 1.00 & \\
\hline Yes & $1.36^{* * *}$ & $(1.09-1.69)$ & $0.57^{* * *}$ & $(0.38-0.85)$ \\
\hline \multicolumn{5}{|l|}{ Current marital status } \\
\hline Currently married & 1.00 & & 1.00 & \\
\hline Currently not married & $1.12^{* *}$ & $(1.01-1.25)$ & 1.06 & $(0.76-1.47)$ \\
\hline \multicolumn{5}{|l|}{ Level of education } \\
\hline No formal schooling & 1.00 & & 1.00 & \\
\hline Less than 5 years of schooling & 1.06 & $(0.93-1.21)$ & 0.76 & $(0.52-1.10)$ \\
\hline $6-10$ years of schooling & 0.94 & $(0.81-1.10)$ & 0.72 & $(0.45-1.13)$ \\
\hline More than 10 years of schooling & 1.01 & $(0.83-1.22)$ & 0.82 & $(0.45-1.52)$ \\
\hline \multicolumn{5}{|l|}{ Working status } \\
\hline Working & 1.00 & & 1.00 & \\
\hline Not working & $1.21^{* * *}$ & $(1.06-1.39)$ & 1.34 & $(0.80-2.23)$ \\
\hline \multicolumn{5}{|l|}{ Household headship status } \\
\hline No & 1.00 & & 1.00 & \\
\hline Yes & 1.09 & $(0.95-1.25)$ & 0.94 & $(0.63-1.38)$ \\
\hline \multicolumn{5}{|l|}{ Family structure } \\
\hline Joint/Extended & 1.00 & & 1.00 & \\
\hline
\end{tabular}


Table 3 Odds ratio from logistic regression models showing the association of bio-demographic and socio-economic characteristics measure in round-I with acquiring and recovery from disability during round-II among panel data of older adults (Continued)

\begin{tabular}{|c|c|c|c|c|}
\hline \multirow[t]{3}{*}{ Characteristics } & \multicolumn{4}{|c|}{ Change in disability status during round-II } \\
\hline & \multicolumn{2}{|c|}{ Disability acquired } & \multicolumn{2}{|c|}{ Disability recovered } \\
\hline & $\overline{\mathrm{OR}}$ & $95 \% \mathrm{Cl}$ & $\overline{\mathrm{OR}}$ & $95 \% \mathrm{Cl}$ \\
\hline Nuclear & 0.93 & $(0.80-1.09)$ & 1.17 & $(0.72-1.88)$ \\
\hline Single generation & $1.35^{* * *}$ & $(1.16-1.57)$ & 1.07 & $(0.71-1.62)$ \\
\hline \multicolumn{5}{|c|}{ Household wealth quintile } \\
\hline Poorest & 1.00 & & 1.00 & \\
\hline Poor & 0.93 & $(0.80-1.09)$ & $1.58^{*}$ & $(0.92-2.72)$ \\
\hline Medium & $0.83^{* *}$ & $(0.71-0.97)$ & $2.16^{* * *}$ & $(1.27-3.69)$ \\
\hline Rich & 0.88 & $(0.75-1.04)$ & $2.03^{* *}$ & $(1.16-3.53)$ \\
\hline Richest & 0.92 & $(0.76-1.11)$ & $2.38^{* * *}$ & $(1.31-4.33)$ \\
\hline
\end{tabular}

Household below poverty line (BPL)

No

Yes

\section{Caste of household}

Scheduled Tribes

Scheduled Castes

Other Backward Classes

Others

\section{Religion of household}

Hindu

Muslim

Others

\section{Participates in social group}

Yes

No

Place of residence

\section{Urban}

Rural

\section{Country regions}

Northern

North Eastern

Central

Eastern

Western

Southern

Number of older adults

\subsection{0}

1.02

\subsection{0}

1.19

1.19

1.08

1.00

0.97

$1.16^{*}$

1.00

1.03

\subsection{0}

1.05

1.00

$0.18^{* * *}$

$2.72^{* * *}$

$0.75^{* * *}$

$0.70^{* * *}$

$1.40^{* * *}$

9,533

(0.91-1.15)

1.00

1.12

(0.74-1.69)

1.00

$0.50^{*}$

$0.44^{* *}$

$0.40^{* *}$

(0.23-1.06)

(0.96-1.47)

(0.86-1.34)

(0.22-0.90)

(0.19-0.83)

1.00

(0.82-1.13)

(0.81-2.11)

(0.97-1.38)

1.31

0.82

(0.51-1.30)

(0.93-1.13)

1.00

1.26

(0.93-1.70)

Note - (a) Categories with odds ratio 1.00 are the reference category (b) ${ }^{*}$ denotes $p$-value $<0.1,{ }^{* *}$ denotes $p$-value $<0.05,{ }^{* * *}$ denotes $p$-value $<0.01$ (c) OR: Odds ratio (d) $95 \%$ Confidence interval $(\mathrm{Cl})$ is given in brackets

\section{Discussion}

The present study uses the panel dataset of IHDS (200405 and 2011-12), which aims to capture the dynamics of older adults acquiring or getting recovered from disability. It was found that about $32 \%$ of older adults acquired disability from 2004 to 05 to $2011-12$ and about $4 \%$ of older adults got recovered during the same period. Moreover, in 2011-12 nearly $37 \%$ of older adults were disabled in comparison to $9 \%$ in 2004-05. It was argued by WHO that the prevalence of disability among older adults is increasing drastically due to changing demographic trends, that is, an increase in the share of older 
adults and due to an increase in chronic health condition among older adults [48].

Older women had a higher likelihood of acquiring disability than older men. The results were consistent with the previous literature which argued that gender differences do exist as women develop disability more often than men do as their survival rates are higher than men [49]. Oldest-old had higher odds to acquire disability along with lower odds for recovering from disability than younger older adults. The results were parallel with the previous finding that the occurrence of disability increases with the ageing population [50]. Previous studies found an association of chronic morbidities with the prevalence of disability $[51,52]$, and a few studies concluded that chronic diseases contribute significantly to the procurement of disability among older adults [51, 53]. Consistently, the present study found that older adults with any chronic disease had a higher likelihood to acquire a disability.

Older adults with non-working status had higher odds to acquire a disability as compared to those with working status. The plausible reason is that older adults who were in non-working category were most likely to acquire the sedentary life style in later stages of life [54]. A sedentary life style lead to the acquisition of pathology (acute or chronic diseases, injury) and results in functional limitations which finally leads to disability [54]. Disability among older adults hinders the working status and hence poses an economic burden among older adults [55]. Marital status had a protective effect towards acquiring disability in older ages. The results are consistent with the previous findings [56]. Older adults coresiding may be dependent on others for household chores; hence being married was also associated with a higher chance of recovery. The older adults living in the single-generation household had a higher likelihood to acquire a disability. Similar findings were visible in the previous studies that older adults living in single generation households had a higher likelihood to suffer from the disability [57]. In a single-generation household, the older adults are not dependent on others to be taken care of financially nor in any household chores [57]. Yet, we cannot fully dismiss the probability that disability determines living arrangements rather than living arrangements impacting disability in the present research.

Further, present analysis found that the older adults who belonged to the richest household wealth quintile had a higher likelihood to recover from a disability. Earlier studies concluded that older adults from lower socioeconomic classes had a higher risk for activities of daily living, instrumental activities of daily living, and functional limitations [39], indicating a higher prevalence rates and lower recovery rate due to health resource constraints. Moreover, a longitudinal analysis suggested that self-perceived income adequacy predicts the median age for onset of disability and lower levels of perceived income result in poor health outcomes among older adults [58]. Additionally, it was earlier argued that treatment-seeking was higher among older adults from the richest wealth quintile and higher castes in comparison to their counterparts with low socioeconomic status [40], possibly leading to lower recovery rates among low socioeconomic groups. On the other hand, low caste groups were found to be more likely to recover from disability and the odds were comparatively lower but insignificant in the case of acquiring disability over the period. This can partially be explained by the absence of a large portion base-line sample in the second round who could not survive and the higher recovery rate among those who survived both the rounds.

Older adults from the central and southern regions were more likely to acquire a disability in comparison to those from the northern region of India. The relationship is quite spurious in the case of southern India as most of the states from southern India tops in the health index score in a report by NITI Ayog (National Institution for Transforming India) [59]. However, the condition of health care infrastructure is not improving in the states like Madhya Pradesh, Uttar Pradesh, and Chhattisgarh which fall into the central Indian region had low rank in health index score [59]. The association also needs further investigation as it was found in previous studies that treatment-seeking was higher in southern states of India [40]. However, the probable reason for the higher occurrence of disability among older adults in southern India may be due to a higher proportion of older adults in the respective region [60].

In comparison to other literature from India, the present study backs different strengths. Firstly, we used the nationally representative database which contains prominent information on disability. Secondly, the panel nature of the dataset allows us to track the changes in disability status among the same individual and provide evidence of its association with different characteristics of the elderly. The results of this study emphasize from a public health perspective, the need of the hour to focus on the growing prevalence of disability across the Indian elderly. This study also had certain limitations. Although the panel sample is largely similar to the baseline sample by the individual and household socio-economic characteristics, the findings of our study are affected by attrition bias. Therefore, the results need to be interpreted carefully. Further, the disease taken into consideration were self-reported and may include reporting bias. Moreover, due to limited information on disability in the data, the study had restricted its analysis to certain physical limitations only. Additionally, the findings from our study do not claim causal effect. However, with the help 
of relevant data future studies need to examine whether change in determinants like chronic diseases, marital status, working status, etc. led to the transition in disability status among the older adults.

\section{Conclusions}

The present study focused on acquiring and recovery from disability among older adults in India from 2004 to 05 to 2011-12. The study emphasized the importance of considering chronic physical diseases and several sociodemographic factors that may negatively affect the trajectory of disability in older ages. Older adults who had any chronic disease, were in non-working category, from single generation household and southern region should be in focus as they are at higher risk for acquiring the disability. Older adults from poorest household quintile should be prioritize and subsidized medical health facility should be provided so that they can go for treatment if acquired disability due to certain underlying causes. Even central region of India needs special attention for better medical facilities to older adults. Further, policymakers should develop joint programs focused on health promotion, and the development of disability prevention in the older population.

\section{Abbreviations}

OR: Odds Ratio; Cl: Confidence Interval; IHDS: India Human Development Survey; OBC: Other Backward Classes; SC: Scheduled Caste; ST: Scheduled Tribe

\section{Acknowledgements}

Not applicable.

\section{Authors' contributions}

The concept was drafted by RP and SS; RR contributed to the analysis design, RP, RR and MT advised on the paper and assisted in paper conceptualization. SS and MT contributed to the comprehensive writing of the article. All authors read and approved the final manuscript.

\section{Funding}

Authors did not receive any funding to carry out this research.

\section{Availability of data and materials}

The IHDS datasets used in our study can be downloaded from the InterUniversity Consortium for Political and Social Research (ICPSR) data repository at http://www.icpsr.umich.edu.

\section{Declarations}

\section{Author's Information}

Ronak Paul and Rashmi completed their M.Phil. in Biostatistics and Demography and currently pursuing their Ph.D. in Biostatistics and Demography from International Institute for Population Sciences, Mumbai. Shobhit Srivastava and Muhammad T completed their M.Phil. in Population Studies and currently pursuing their Ph.D. in Population Studies from International Institute for Population Sciences, Mumbai.

\section{Ethics approval and consent to participate}

Not Applicable. Our study utilized publicly available secondary datasets with no information that could lead to the identification of the respondents. Therefore, prior ethical approval for using the datasets was not required.

\section{Consent for publication}

Not applicable.

\section{Competing interests}

The authors declare that they have no competing interests.

Received: 28 February 2021 Accepted: 2 July 2021

Published online: 16 July 2021

References

1. Reza A, Nicole H, Nenad B, et al. Socio-demographic patterns of disability among older adult populations of low-income and middle-income countries: results from World Health Survey. Int J Public Health 2016;61:33745 .

2. Lestari SK, Ng N, Kowal P, et al. Diversity in the Factors Associated with ADL-Related Disability among Older People in Six Middle-Income Countries: A Cross-Country Comparison. Int J Environ Res Public Health 2019;16:1341.

3. Prakash IJ. Aging, disability, and disabled older people in India. J Aging Soc Policy 2003;15:85-108.

4. Kumar Sg, Roy G, Kar S. Disability and rehabilitation services in India: Issues and challenges. J Fam Med Prim Care 2012;1:69.

5. Kowal P, Williams S, Jiang Y, et al. Aging, Health, and Chronic Conditions in China and India: Results from the Multinational Study on Global AGEing and Adult Health (SAGE). In: Smith J, Majmundar M (eds) National Research Council (US) Panel on Policy Research and Data Needs to Meet the Challenge of Aging in Asia. 2012, pp. 415-437.

6. He W, Muenchrath MN, Kowal PR. Shades of gray: a cross-country study of health and well-being of the older populations in SAGE countries, 20072010. US Census Bur 2012:2007-10.

7. Banks LM, Kuper H, Polack S. Poverty and disability in low- and middleincome countries: A systematic review. PLoS One 2017;12:e0189996.

8. Ta Ü, Steyerberg EW, Bierma-zeinstra SMA, et al. Age, gender and disability predict future disability in older people: the Rotterdam Study. BMC Geriatr; 11.

9. Dunlop DD, Manheim LM, Sohn M, et al. Incidence of Functional Limitation in Older Adults: The Impact of Gender, Race, and Chronic Conditions. 2002; 83:964-71.

10. Ouden MEM Den, Schuurmans MJ, Mueller-schotte S, et al. Domains Contributing to Disability in Activities of Daily Living. J Am Med Dir Assoc 2013;14:18-24.

11. Anand A, Syamala TS, Sk IK, et al. Understanding Frailty, Functional Health and Disability among Older Persons in India: A Decomposition Analysis of Gender and Place of Resident. Hamadan Univ Med Sci 2020;20:e00484..

12. Hosseinpoor AR, Williams JS, Jann B, et al. Social determinants of sex differences in disability among older adults: a multi-country decomposition analysis using the World Health Survey. 2012;1-8.

13. Stewart Williams J, Norström F, Ng N. Disability and ageing in China and India - Decomposing the effects of gender and residence. Results from the WHO study on global AGEing and adult health (SAGE). BMC Geriatr 2017;17: $1-13$

14. Firenze AS, Regional T, Agency $\mathrm{H}$, et al. Risk factors for disability in older persons over. 2010;92-8.

15. Ta Ü, Verhagen AP, Bierma-zeinstra SMA, et al. Incidence and risk factors of disability in the elderly: The Rotterdam Study. 2007:44:272-8.

16. Tak E, Kuiper $R$, Chorus $A$, et al. Prevention of onset and progression of basic ADL disability by physical activity in community dwelling older adults: A meta-analysis. Ageing Res Rev 2013;12:329-38.

17. Palacios-Ceña D, Jiménez-García R, Hernández-Barrera V, et al. Has the prevalence of disability increased over the past decade (2000-2007) in elderly people? A spanish population-based survey. J Am Med Dir Assoc 2012;13:136-42.

18. Basu S, King AC. Disability and chronic disease among older adults in India: Detecting vulnerable populations through the WHO SAGE Study. Am J Epidemiol 2013;178:1620-28.

19. Gomez-olive FX, Schröders J, Aboderin I, et al. Variations in disability and quality of life with age and sex between eight lower income and middle-income countries: data from the INDEPTH WHO-SAGE collaboration. 2017;1-11.

20. Rahman MHU, Singh A. Socio-economic disparity in the occurrence of disability among older adults in six low and middle income countries. Int J Hum Rights Healthc. Epub ahead of print 2018. https://doi.org/10.1108/ IJHRH-05-2018-0034.

21. MacLeod S, Musich S, Hawkins K, et al. The impact of resilience among older adults. Geriatr Nurs (Minneap) 2016;37:266-72. 
22. Pérès $\mathrm{K}$, Verret $\mathrm{C}$, Alioum $\mathrm{A}$, et al. The disablement process: Factors associated with progression of disability and recovery in French elderly people. Disabil Rehabil 2005; 27: 263-276.

23. Boyd CM, Landefeld CS, Counsell SR, et al. Recovery of activities of daily living in older adults after hospitalization for acute medical illness. J Am Geriatr Soc 2008; 56: 2171-2179.

24. Díaz-Venegas C, Wong R. Recovery from physical limitations among older Mexican adults. Arch Gerontol Geriatr 2020; 91: 104208

25. Nelson ME, Rejeski WJ, Blair SN, et al. Physical activity and public health in older adults: Recommendation from the American College of Sports Medicine and the American Heart Association. Circulation 2007; 116: 1094 1105.

26. Janevic MR, Janz NK, Dodge JA, et al. Longitudinal effects of social support on the health and functioning of older women with heart disease. Int J Aging Hum Dev 2004; 59: 153-175.

27. Gu D, Vlosky DA, Yi Z. Gender differentials in transitions and expected years spent in seven living arrangements among the oldest-old in china - a population-based decrement- increment life table analysis. 2009.

28. Gu D, Yi Z. Sociodemographic effects on the onset and recovery of ADL disability among Chinese oldest-old. Demogr Res 2004; 11: 1-41.

29. Saikia N, Bora JK, Jasilionis D, et al. Disability divides in India: Evidence from the 2011 census. PLoS One 2016; 11: 1-12.

30. Samanta T, Chen F, Vanneman R. Living Arrangements and Health of Older Adults in India. Journals Gerontol - Ser B Psychol Sci Soc Sci 2015; 70: 937 947.

31. Pandey MK. Poverty and disability among Indian elderly: Evidence from household survey. J Disabil Policy Stud 2012; 23: 39-49.

32. Perkins JM, Lee $\mathrm{H}$ young, James KS, et al. Marital status, widowhood duration, gender and health outcomes: a cross-sectional study among older adults in India. BMC Public Health 2016;16:1-12.

33. Biritwum RB, Minicuci N, Yawson AE, et al. Prevalence of and factors associated with frailty and disability in older adults from China, Ghana, India, Mexico, Russia and South Africa. Maturitas 2016; 91: 8-18.

34. Srivastava S, Muhammad T. Violence and associated health outcomes among older adults in India: A gendered perspective. SSM - Popul Heal; 12. Epub ahead of print 1 December 2020. https://doi.org/10.1016/j.ssmph.202 0.100702 .

35. Muhammad T, Srivastava S. Why Rotational Living Is Bad for Older Adults ? Evidence from a Cross- Sectional Study in India. J Popul Ageing; 1. Epub ahead of print 2020. https://doi.org/10.1007/s12062-020-09312-4.

36. Velayutham B, Kangusamy B, Joshua $V$, et al. The prevalence of disability in elderly in India - Analysis of 2011 census data. Disabil Health J 2016; 9: 584 592.

37. Nagarkar A, Kashikar Y. Predictors of functional disability with focus on activities of daily living: A community based follow-up study in older adults in India. Arch Gerontol Geriatr 2017; 69: 151-155.

38. Sengupta M, Agree EM. Gender and disability among older adults in north and south India: Differences associated with coresidence and marriage. J Cross Cult Gerontol 2003; 17: 313-336

39. Ramsay SE, Whincup PH, Morris RW, et al. Extent of Social Inequalities in Disability in the Elderly: Results From a Population-based Study of British Men. Ann Epidemiol. Epub ahead of print 2008. https://doi.org/10.1016/j.a nnepidem.2008.09.006

40. Srivastava S, Gill A. Untreated morbidity and treatment-seeking behaviour among the elderly in India: Analysis based on National Sample Survey 2004 and 2014. SSM - Popul Heal 2020; 100557.

41. Desai S, Vanneman R, National Council Of Applied Economic Research ND. India Human Development Survey (IHDS), 2005: Version 12 [Data set]. InterUniversity Consortium for Political and Social Research.

42. Desai S, Vanneman R. India Human Development Survey-II (IHDS-II), 2011 12: Version 6 [Data set]. Inter-University Consortium for Political and Social Research.

43. Desai SB, Dubey A, Joshi BL, et al. Human Development in India: challenges for a society in transition. Challenges a Soc Transit 2010; 1-261.

44. Desai S, Dubey A, Vanneman R. India Human Development Survey-II Users' Guide Release 01. University of Maryland and National Council of Applied Economic Research, New Delhi.

45. Filmer D, Scott K. Assessing asset indices. The World Bank, 2008.

46. Cameron AC, Trivedi PK. Microeconometrics: Methods and Applications. Cambridge University Press.

47. StataCorp. Stata: Release 14. Statistical Software. 2015
48. World Health Organization. Disability and health. WHO

49. Guralnik JM, Leveille SG, Hirsch R, et al. The impact of disability in older women. J Am Med Womens Assoc; 52.

50. Manini T. Development of Physical Disability in Older Adults. Curr Aging Sci. Epub ahead of print 2012. https://doi.org/10.2174/1874609811104030184.

51. Parmar MC, Saikia N. Chronic morbidity and reported disability among older persons from the India Human Development Survey. BMC Geriatr 2018; 18: $1-12$.

52. Kastor A, Mohanty SK. Associated Covariates of Functional Limitation Among Older Adults in India: an Exploration. Ageing Int 2016; 41: 178-192.

53. Sousa RM, Ferri CP, Acosta D, et al. Contribution of chronic diseases to disability in elderly people in countries with low and middle incomes: a 10/ 66 Dementia Research Group population-based survey. Lancet. Epub ahead of print 2009. https://doi.org/10.1016/50140-6736(09)61829-8.

54. Heikkinen E. Disability and physical activity in late life-research models and approaches. European Review of Aging and Physical Activity. Epub ahead of print 2006. https://doi.org/10.1007/s11556-006-0004-8.

55. Levy NB. Pain and Disability: Clinical, Behavioral, and Public Policy Perspectives. Am J Psychiatry. Epub ahead of print 1989. https://doi.org/1 0.1176/ajp.146.9.1228.

56. Hébert R, Brayne C, Spiegelhalter D. Factors associated with functional decline and improvement in a very elderly community-dwelling population. Am J Epidemiol. Epub ahead of print 1999. https://doi.org/10.1093/ oxfordjournals.aje.a010039.

57. Schatz E, Ralston M, Madhavan S, et al. Living arrangements, disability and gender of older adults among rural South Africa. Journals Gerontol - Ser B Psychol Sci Soc Sci. Epub ahead of print 2018. https://doi.org/10.1093/ geronb/gbx081.

58. Matthews RJ, Smith LK, Hancock RM, et al. Socioeconomic factors associated with the onset of disability in older age: A longitudinal study of people aged 75 years and over. In: Social Science and Medicine. 2005. Epub ahead of print 2005. https://doi.org/10.1016/j.socscimed.2005.02.007.

59. NITI Aayog. HEALTHY STATES PROGRESSIVE INDIA. 2019.

60. Mishra VK. India's Projected Aged Population (65+), Projected Life Expectancy at Birth and Insecurities Faced by Aged Population. Ageing Int. Epub ahead of print 2020. https://doi.org/10.1007/s12126-019-09350-0.

\section{Publisher's Note}

Springer Nature remains neutral with regard to jurisdictional claims in published maps and institutional affiliations.
Ready to submit your research? Choose BMC and benefit from:

- fast, convenient online submission

- thorough peer review by experienced researchers in your field

- rapid publication on acceptance

- support for research data, including large and complex data types

- gold Open Access which fosters wider collaboration and increased citations

- maximum visibility for your research: over $100 \mathrm{M}$ website views per year

At $\mathrm{BMC}$, research is always in progress.

Learn more biomedcentral.com/submissions 